Subscriber access provided by Caltech Library

\title{
Article
}

\section{Si-doped Fe Catalyst for Ammonia Synthesis at Dramatically Decreased Pressures and Temperatures}

\author{
Qi An, Molly Mcdonald, Alessandro Fortunelli, and William A. Goddard
}

J. Am. Chem. Soc., Just Accepted Manuscript • DOI: 10.1021/jacs.9b13996 • Publication Date (Web): 09 Apr 2020

Downloaded from pubs.acs.org on April 9, 2020

\section{Just Accepted}

"Just Accepted" manuscripts have been peer-reviewed and accepted for publication. They are posted online prior to technical editing, formatting for publication and author proofing. The American Chemical Society provides "Just Accepted" as a service to the research community to expedite the dissemination of scientific material as soon as possible after acceptance. "Just Accepted" manuscripts appear in full in PDF format accompanied by an HTML abstract. "Just Accepted" manuscripts have been fully peer reviewed, but should not be considered the official version of record. They are citable by the Digital Object Identifier (DOI®). "Just Accepted" is an optional service offered to authors. Therefore, the "Just Accepted" Web site may not include all articles that will be published in the journal. After a manuscript is technically edited and formatted, it will be removed from the "Just Accepted" Web site and published as an ASAP article. Note that technical editing may introduce minor changes to the manuscript text and/or graphics which could affect content, and all legal disclaimers and ethical guidelines that apply to the journal pertain. ACS cannot be held responsible for errors or consequences arising from the use of information contained in these "Just Accepted" manuscripts. 


\begin{abstract}
The Haber-Bosch $(\mathrm{HB})$ process combining nitrogen $\left(\mathrm{N}_{2}\right)$ and hydrogen $\left(\mathrm{H}_{2}\right)$ into ammonia $\left(\mathrm{NH}_{3}\right)$ gases plays an essential role in the synthesis of fertilizers for food production and many other commodities. However, HB requires enormous energy resources $(2 \%$ of world energy production) and the high pressures and temperatures make $\mathrm{NH}_{3}$ production facilities very expensive. Recent advances in improving HB catalysts have been incremental and slow. To accelerate the development of improved HB catalysts, we developed a hierarchical highthroughput catalyst screening (HHTCS) approach based on the recently developed complete reaction mechanism to identify non-transition metal (NTM) elements from a total set of 18 candidates that can significantly improve the efficiency of the most active Fe surface, Febcc(111), through surface and subsurface doping. Surprisingly, we found a very promising subsurface dopant, $\mathrm{Si}$, that had not been identified nor suggested previously, showing the importance of the subsurface $\mathrm{Fe}$ atoms in $\mathrm{N}_{2}$ reduction reactions. Then we derived the full reaction path of the HB process for the Si doped Fe-bcc(111) from QM simulations which we combined with kinetic Monte Carlo (kMC) simulations to predict a 13-fold increase in turnover frequency (TOF) under typical extreme HB conditions (200 atm reactant pressure and 500 ${ }^{\circ} \mathrm{C}$ ) and a $\sim 43$-fold increase in TOF under ideal HB conditions (20 atm reactant pressure and 400 ${ }^{\circ} \mathrm{C}$ ) for the Si-doped Fe catalyst, compared to pure Fe catalyst. Importantly, the $\mathrm{Si}$ doped $\mathrm{Fe}$ catalyst can achieve the same TOF of pure Fe at $200 \mathrm{~atm} / 500{ }^{\circ} \mathrm{C}$ under much milder conditions: e.g., at a much decreased reactant pressure of $20 \mathrm{~atm}$ at $500{ }^{\circ} \mathrm{C}$, or alternatively at temperature and reactant pressure decreased to $400{ }^{\circ} \mathrm{C}$ and $50 \mathrm{~atm}$, respectively. Production plants using the new catalysts that operate under such milder conditions could be much less expensive, allowing production at local sites needing fertilizer.
\end{abstract}




\section{INTRODUCTION}

The Haber-Bosch (HB) process plays an essential role in feeding the increasing word populations as a key intermediate in the production of nitrogen fertilizers, as well as in many other applications such as explosives for civil construction. ${ }^{1,2}$ The HB process synthesizes ammonia $\left(\mathrm{NH}_{3}\right)$ by combining dinitrogen $\left(\mathrm{N}_{2}\right)$ from air and dihydrogen $\left(\mathrm{H}_{2}\right)$ from petroleum products. ${ }^{3}$ It has been the first industrial chemical process to use high pressures, and it is still one of the most energy-demanding, consuming $\sim 1-2 \%$ of the world's energy and producing $\sim 1.5$ tons of the carbon dioxide per ton of $\mathrm{NH}_{3}$ because of the extreme reaction conditions of high temperatures $\left(400-600^{\circ} \mathrm{C}\right)$, very high pressures $(200-400 \mathrm{~atm})$, and the sheer amount of $160+$ million tons of ammonia needed yearly. ${ }^{4}$ Iron $(\mathrm{Fe})$ and ruthenium $(\mathrm{Ru})$ based catalysts are the most efficient catalysts for ammonia synthesis, with iron-based catalysts widely used in modern industrial process because of their non-toxicity and low cost. ${ }^{5}$ Promoters such as alkali and alkaline earth metal oxides ${ }^{6-10}$ have long been employed to enhance activity, ${ }^{8-10}$ but the development of HB catalysts over the past century has been incremental and slow. Moreover, although it is thought that the most recent systems incorporate elements other than Fe and alkalis, the true composition of the industrial catalysts is not in the public domain, neither as journal publications nor as patents. Recently, neutron diffraction experiments were performed on industrial Fe catalysts at $\mathrm{HB}$ conditions, ${ }^{11}$ indicating that the bulk of the industrial catalyst retains a bcc crystal structure but exhibits a complex and defective microstructure that may cause the high catalytic performance. The present status is that industrial synthesis of ammonia cannot be performed under mild conditions, requiring huge plants with an annual capacity over 200,000 $\mathrm{NH}_{3}$ tons and investments of 1000-2000 US\$ per $\mathrm{NH}_{3}$ ton to be economically advantageous. ${ }^{12}$ Thus, novel heterogeneous catalysts enabling an efficient HB process under mild conditions are strongly needed. Over the last century a number of improvements have been made in HB technology with trial-and-error experimental studies. However, the development of catalysts is limited by decreasing $\mathrm{N}_{2}$ dissociation barrier while retaining sufficiently large $\mathrm{N}_{2}$ binding energies to improve the catalytic efficiency. ${ }^{13}$

Photocatalytic and electrochemical pathways for ammonia synthesis have been investigated recently. ${ }^{14-18}$ Although the electroreduction of $\mathrm{N}_{2}$ to ammonia can be achieved at room temperatures and atmospheric pressures, ${ }^{14}$ its scale-up to industry production remains a huge challenge. 
We propose that the way forward is theory-based rational design in which rigorous knowledge on reaction mechanism and catalytic activity are used to identify the features required in an optimal catalyst. An initial step was our application of extensive quantum mechanics (QM) simulations to derive detailed reaction pathways of the $\mathrm{HB}$ process on two most active $\mathrm{Fe}$ surfaces: $\mathrm{Fe}(111)^{19}$ and $\mathrm{Fe}(211)^{20}$. We then used this QM information on catalytic mechanisms and rate-determined steps (RDS) in kinetic Monte Carlo (kMC) modeling to predict actual rates under steady-state conditions. For $\mathrm{Fe}(111)$, considering 12 important reaction steps and 24 reaction intermediates, we predicted a turn-over frequency (TOF) of $17.7 \mathrm{NH}_{3} / \mathrm{sec}$ on a $(2 \times 2)$ unit cell at $400{ }^{\circ} \mathrm{C}, 20 \mathrm{~atm}$ reactant total pressure, and 1.5 Torr $(0.002 \mathrm{~atm}) \mathrm{NH}_{3}$ pressure, agreeing very well with single-crystal experimental results of $9.7 \mathrm{NH}_{3} /$ second under the same conditions. ${ }^{21}$

Moreover, for the missing row $(2 \times 1)$-reconstructed $\mathrm{Fe}(211) \mathrm{R}$ surface ${ }^{20}$ we predicted a TOF of $18.7 \mathrm{NH}_{3} / \mathrm{sec}$ at 1.5 Torr $(0.002 \mathrm{~atm}) \mathrm{NH}_{3}$ pressure and $3.5 \mathrm{NH}_{3} / \mathrm{sec}$ at $1 \mathrm{~atm} \mathrm{NH}_{3}$ pressure. The experimental ratio between (211) and (111) rates at low (undisclosed) $\mathrm{NH}_{3}$ pressure was reported to be $0.75 .{ }^{21}$ Thus, our prediction is in very good agreement with experiment, ${ }^{21,22}$ validating the accuracy of our combined QM/kMC modeling.

Based on these solid grounds, we used the accumulated information to design improved catalysts. Developing novel HB catalysts is challenging because of the complex reaction pathway. The Sabatier principle ${ }^{23}$ or volcano curve modeling ${ }^{24}$ have been successfully applied to simple catalytic processes that involves one key or two rate-determining steps. Campbell et al. developed a catalyst design approach using a combination of RDSs depending on the degree-ofrate-control (DRC) indexes, which however focuses on steps that are rate-determining for a given catalyst. ${ }^{25}$

To overcome these issues, we developed a hierarchical high-throughput catalyst screening (HHTCS) approach applicable in general to complex catalytic reaction systems, but based on QM-derived full reaction network simplified to examine only the reaction steps likely to be rate determining. ${ }^{26}$ This HHTCS selected four distinct processes most likely to become RDS: (1) the activation of the N-N bond; (2) the hydrogenation of $\mathrm{NH}_{\mathrm{x}}$-adsorbed species; (3) $\mathrm{NH}_{3}$ desorption from the surface; and (4) poisoning of catalytically active sites by reactants $\left(\mathrm{H}_{2}\right.$, hydrogen poisoning) species. We then arranged the free-energy barriers of these 4 steps in a decreasing 
order. By considering a catalyst change such as doping at specific sites, we estimated how dopants modify the 4 RDS barriers to screen out promising candidate alloys hierarchically, i.e., restricting each step only to candidates passing the previous screening (i.e., decreasing the barriers of the previous steps).

We then added a stability test to guarantee that the proposed candidates are robust under reaction conditions. Finally, we reconstructed the free-energy diagram and predicted the TOF via $\mathrm{kMC}$ of the most promising dopant (with the lowest overall barrier in the examined set), compared to pure Fe. In the case of surface doping of Fe-bcc(111), screening 34 transition metal (TM) dopants we identified a small set of candidates ( $\mathrm{Rh}, \mathrm{Pt}, \mathrm{Pd}, \mathrm{Cu}$ ) among which the most promising, Rh, was found to increase the TOF by a factor of $\sim 3.3$ compared to Fe(111), ${ }^{26}$ while Co-doping increases the TOF by a factor of $\sim 2.3 .{ }^{27}$ We then applied HHTCS to subsurface doping of Fe-bcc(111) with the same set of 34 TM dopants and found that, among a small set of two promising candidates ( $\mathrm{Co}$ and $\mathrm{Ni}$ ), the most promising $(\mathrm{Ni})$ leads to a 16 -fold increase in $\mathrm{HB}$ TOF compared to the pure $\mathrm{Fe}(111)$ surface at $400{ }^{\circ} \mathrm{C}$ and $20 \mathrm{~atm} .{ }^{28}$

Here, we apply the HHTCS approach to non-transition-metals (NTM) elements as dopants in both surface and subsurface sites of Fe-bcc(111). Surprisingly, Si is screened out as the best candidate with the catalytic efficiency of Fe-Si catalyst significantly improved compared to pure $\mathrm{Fe}$ or previously identified dopants. The RDS for Fe-Si catalyst also changes to the hydrogenation step compared to pure $\mathrm{Fe}^{19}$ and other doped systems examined previously. ${ }^{26-28}$ The kMC analysis, based on the QM-derived complete free-energy diagram, suggests a $\sim 13$-fold increase in TOF under $200 \mathrm{~atm}$ reactant pressure and $500{ }^{\circ} \mathrm{C}$ and a $\sim 43$-fold increase in TOF under $20 \mathrm{~atm}$ reactant pressure and $400^{\circ} \mathrm{C}$. The $\mathrm{kMC}$ analysis also indicates that the same TOF of pure Fe under typical, extreme HB industrial conditions $\left(200 \mathrm{~atm}, 500{ }^{\circ} \mathrm{C}\right)$ could be achieved by decreasing the reaction pressure to $20 \mathrm{~atm}$ or simultaneously the reactant pressure to $50 \mathrm{~atm}$ and reaction temperature to $400{ }^{\circ} \mathrm{C}$, thus potentially leading to a breakthrough in $\mathrm{HB}$ production costs and proposing Si as a novel dopant to be considered in future catalytic design for the HB process.

Indeed, experiments show that the rate of ammonia synthesis on single crystal Fe bcc $(111)^{21}$ is comparable with the industrial Fe catalysts with a composition of $94 \% \mathrm{Fe}$ and $5.9 \%$ promoters at $673 \mathrm{~K},{ }^{29}$ suggesting that the catalytic efficiency of the industrial Fe catalyst is closely related to 
that of the single crystal Fe catalyst. We therefore expect that the TOF of industrial catalysts could be improved proportionally if they are synthesized so that they are based on Si-doped Fe systems.

\section{SIMULATION PROCEDURES}

We used the same first-principles approach as discussed in detail in previous studies. ${ }^{19,26,28}$ Most density functional theory (DFT) simulations were performed using VASP software. ${ }^{30-33}$ Besides the surface model, the gas-phases were also simulated in VASP using a large simulation cell $(15 \AA \times 15 \AA \times 15 \AA)$ including vacuum to avoid the interaction with their images. The finite cluster model was applied to derive the zero-point energy and free energy corrections for $\mathrm{N}_{2}, \mathrm{H}_{2}$ and $\mathrm{NH}_{3}$ molecules. ${ }^{19}$

The interaction between valence and core electrons was described using the projector augmented wave method. ${ }^{33}$ The electronic exchange-correlation interactions were described using the Perdew-Burke-Ernzerhof (PBE) furnctional. ${ }^{34,35}$ The van der Waals attraction was considered using the Grimme-D3 empirical corrections ${ }^{36}$ in the Becke-Johnson analytic form. ${ }^{37}$ The PBE-D3 functional predicts a magnetic moment for bulk Fe of $2.16 \mu \mathrm{B}$ in excellent agreement with the experimental value, $2.22 \mu \mathrm{B} .{ }^{38}$ The electron partial occupancies were considered using the tetrahedron method with Blöchl corrections. The plan wave basis set was used in the simulations and an energy cutoff of $500 \mathrm{eV}$ was applied for all elements, which leads to converged energies, forces and geometries. The energy and force convergence were set up to $10^{-6} \mathrm{eV}$ and $10^{-3} \mathrm{eV} / \AA ̊$ for electronic self-consistent field (SCF) and ion relaxation, respectively. The slab model consists of 6 Fe layers, of which the bottom three layers were fixed, and a $15 \AA$ vacuum is applied along the $\mathrm{z}$ direction to avoid the interactions between replicated images. The K-point sampling was chosen to be $4 \times 4 \times 1$. The spin-polarization was applied in all calculations to account for the magnetic momentum of Fe atoms.

The free energy corrections were calculated from the phonon modes assuming the harmonic approximation. The phonon modes were derived from the density functional perturbation theory (DFPT). ${ }^{39}$ Then the energy (E) of phonon systems can be derived from the phonon frequency. Using the thermodynamic relations, entropy (S) and Helmholtz free energy (F = E - TS) can be computed as functions of temperature. ${ }^{40}$ For the slab model, the fixed layers are not accounted in the phonon calculations. The transition state free energy correction was computed using the same 
approach. The phonon calculations also can validate the transition state by showing just one negative frequency. The negative frequency is not counted in the free energy calculations. It worth noting that the harmonic oscillator description is less accurate to describe the translational or rotational modes. Under this circumstance, e.g. the desorption of $\mathrm{NH}_{3}$ and $\mathrm{N}_{2}$ molecules, the zero-point energy (ZPE) corrections were used as the free energy.

\section{RESULTS AND DISCUSSION}

\subsection{HHTCS for Fe bcc(111) over non-transition metal elements}

The $(2 \times 2)$ unit cell of Fe(111) surface and the possible doping sites are displayed in Figure 1(a). We consider both top-layer and subsurface doping sites since we have found that they can potentially affect reaction barriers using TM dopants. We limit to single-atom replacement with the NTM listed in Figure 1(b). Note that we did not include halogens, oxygen, sulfur and carbon (as they likely prefer other sites such as interstitial for carbon), nor radioactive elements that may be not practically utilized in industrial catalysts. Also, it is well-known that exohedral promoters such as potassium can increase HB rates on Fe catalysts. ${ }^{21,41}$ In this manuscript, we will focus on substituted doping on Fe-bcc(111) surface and will discuss the promoter effects only at an explorative level.

(a)

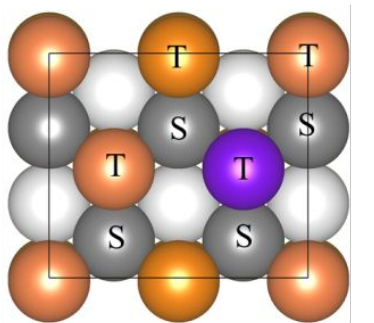

(b)

\begin{tabular}{|c|c|c|c|c|}
\hline $\mathrm{Be}$ & $\mathrm{B}$ & & & \\
\hline $\mathrm{Mg}$ & $\mathrm{Al}$ & $\mathrm{Si}$ & & \\
\hline $\mathrm{Ca}$ & $\mathrm{Ga}$ & $\mathrm{Ge}$ & $\mathrm{As}$ & \\
\hline $\mathrm{Sr}$ & $\mathrm{In}$ & $\mathrm{Sn}$ & $\mathrm{Sb}$ & $\mathrm{Te}$ \\
\hline $\mathrm{Ba}$ & $\mathrm{Tl}$ & $\mathrm{Pb}$ & $\mathrm{Bi}$ & \\
\hline
\end{tabular}

Top surface doping

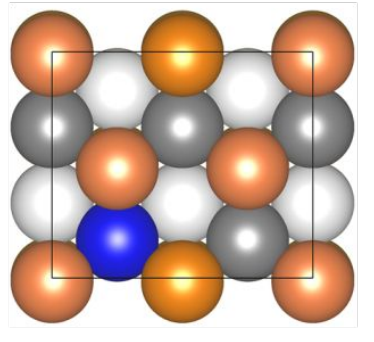

$\mathrm{N}_{2}$ ads-2

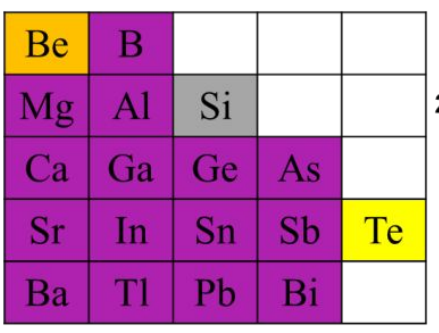

Subsurface doping

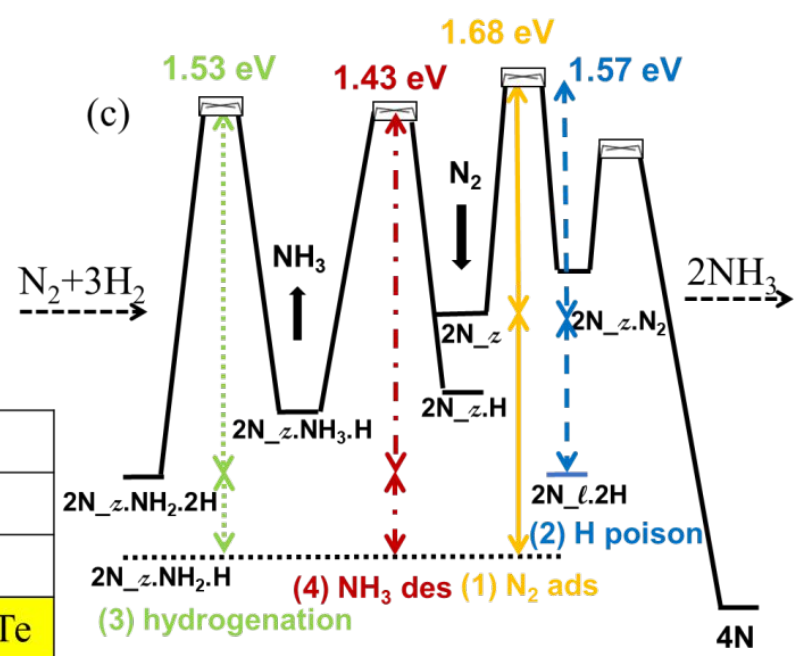

(3) hydrogenation

$4 \mathrm{~N}$
Figure 1. (a) Schematic depictions of the (2x2) unit cell of $\mathrm{Fe}(111)$ with 1 substitutional toplayer dopant (purple) on the left or 1 subsurface dopant (blue) on the right. The top layer, $2^{\text {nd }}$ layer and $3^{\text {rd }}$ layer Fe atoms are represented by bronze, dark grey and white spheres, respectively. 
(b) Portion of the periodic table considered for screening (18 NTM elements). The screening criteria and the dopants screened out on the basis of the corresponding criterion are indicated in magenta (stability), orange $\left(\mathrm{N}_{2}\right.$ adsorption/dissociation), yellow (hydrogen poisoning) colors. Si (in gray) is the only element passing all the criteria. (c) A simplified standard-state free-energy diagram at the DFT/PBE-D3 level for ammonia synthesis over a $(2 \times 2)$ unit cell of the Febcc(111) surface, evaluated at $673 \mathrm{~K}, \mathrm{P}\left(\mathrm{H}_{2}\right)=15 \mathrm{~atm}, \mathrm{P}\left(\mathrm{N}_{2}\right)=5 \mathrm{~atm}$, and $\mathrm{P}\left(\mathrm{NH}_{3}\right)=1 \mathrm{~atm}$. The four barriers selected for high-throughput screening are highlighted in color and numbered as in the text.

To apply HHTCS, we start from the previously derived QM-based free energy diagram for HB on $\mathrm{Fe}(111)$ at $400{ }^{\circ} \mathrm{C}$ and 20 atm reactant pressure, ${ }^{19}$ and we select four primary free-energy barriers (Figure 1(c)) potentially RDS in decreasing order (The full free energy diagram is partitioned and displayed in Figure S1 of supporting information (SI)):

(1) $\mathrm{N}_{2}$ ads-1 (in yellow in Figure 1(c)): adsorption/dissociation of $\mathrm{N}_{2}$ onto the $2 \mathrm{~N}_{3}$ s state (the subfix "," indicates the zig-zag configuration of the two $\mathrm{N}$ atoms, as shown in Figure 2) - free energy barrier of $1.68 \mathrm{eV}$ on pure Fe.

(2) $\mathrm{N}_{2}$ ads-2 or hydrogen poisoning (in blue in Figure 1(c)): $\mathrm{H}_{2}$ poisoning of the $2 \mathrm{~N}$ state via the $2 \mathrm{~N} \_.2 \mathrm{H}$ resting state (the subfix " ?" indicates the linear configuration of the two $\mathrm{N}$ atoms, as shown in Figure 2) - $1.57 \mathrm{eV}$ on pure Fe.

(3) hydrogenation (in green in Figure 1(c)): the hydrogen migration or $\mathrm{H}$ addition to $\mathrm{NH}_{2}-$ $1.53 \mathrm{eV}$ on pure Fe.

(4) $\mathrm{NH}_{3}$ des (in red in Figure 1(c)): $\mathrm{NH}_{3}$ desorption from the $2 \mathrm{~N}_{3} \cdot \mathrm{NH}_{3} \cdot \mathrm{H}$ state $-1.43 \mathrm{eV}$ on pure Fe.

We assume that chemically analogous barriers will follow the trend of these 4 prototypical barriers (e.g., $\mathrm{H}$ migration onto other $\mathrm{NH}_{\mathrm{x}}$ species will follow the trend of $\mathrm{H}$ migration onto $\mathrm{NH}_{2}$ ). Note that we apply the nomenclature defined in previous work, ${ }^{27,28}$ to unambiguously identify dopant configurations with at most 3 absorbates on the surface. The definition of the nomenclature is shown in Figure S2 of the SI. In the nomenclature, we use uppercase letters: A (Nitrogen), B (Vacancy), and C (Hydrogen) to represent the different species on the surface. Then the lowercase letters $(a, b, c)$ represent which species among uppercase letters $(A, B, C)$ the doped element is in vertically. Finally, the letters n, f, and i indicate how close the doped element is to the vacancy spot where $\mathrm{n}, \mathrm{f}$ and i represent near, far, and intermediate, respectively. 
These 4 barriers are then translated into the following HHTCS screening criteria, see Figure 2. Note that we calculate and use electronic energy differences $(\Delta \mathrm{E})$ in these criteria, but apply thermal corrections based on the pure $\mathrm{Fe}(111)$ surface to estimate free-energy differences. The constants appearing in the equations (i.e., $0.102 \mathrm{eV}$ in Eqn. 1, etc.) are based on free-energy corrections of the pure Fe(111) surface, taken from Ref.19. The simulation details can be found in the methodology section. $\Delta \mathrm{E}$ values are reported in the SI (excel file).

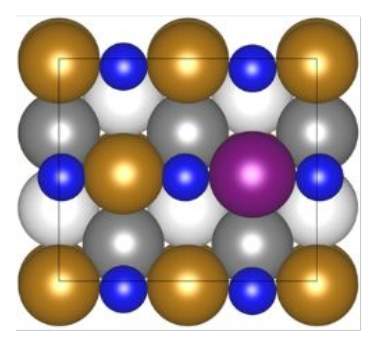

$4 \mathrm{~N}$

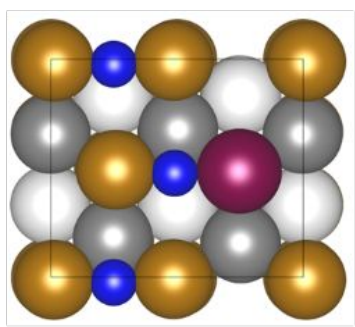

$2 \mathrm{~N}_{z} z$

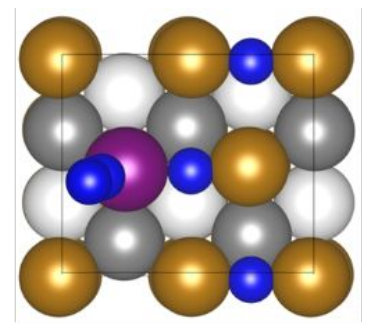

$2 \mathrm{~N} \_z \cdot \mathrm{N}_{2} / \mathrm{n}[\gamma]$

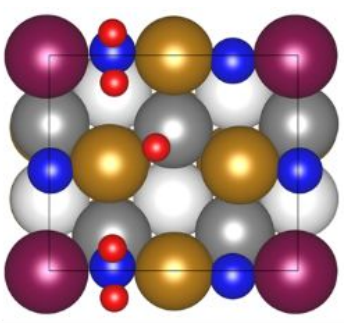

$2 \mathrm{~N}_{-} z \cdot \mathrm{NH}_{2} / \mathrm{n} \cdot \mathrm{H}$

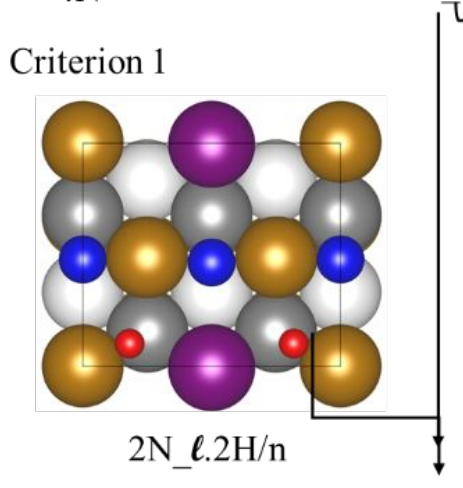

Criterion 3

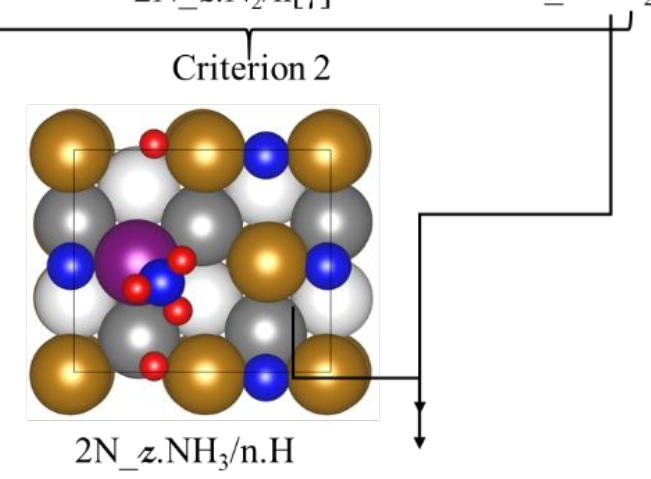

Criterion $4 \& \& 5$

Figure 2. Surface configurations used for estimating critical free energy barrier in each criterion of HHTCS. The nomenclature of each configuration can be referred to Figure S2 in SI. The $2 \mathrm{~N}_{-}$ and $2 \mathrm{~N} \_$represent the diagonal and linear $\mathrm{N}$ configurations, respectively. The $\mathrm{n}$ represents the near doping site to the surface species. The $\gamma$ represents one of the $\mathrm{N}_{2}$ binding configuration ${ }^{19,26}$ among four possible $\mathrm{N}_{2}$ binding configurations shown in Figure $\mathrm{S} 3$ of SI. The surface dopant, $\mathrm{N}$ and $\mathrm{H}$ atoms are represented by purple, blue and red balls, respectively.

Criterion 1: Layer stability. The first criterion is the stability of the dopants in the assigned doping site, highlighted in magenta in Figure 1. For transition metals (TM), most dopants prefer top-layer, ${ }^{25}$ but $\mathrm{Ni}, \mathrm{Co}, \mathrm{Cr}$ prefer to be subsurface. ${ }^{27} \mathrm{We}$ compare the electronic energy of the $4 \mathrm{~N}$ configuration (see Figure 2) with each dopant in 3 sites: top-layer, subsurface and $3^{\text {rd }}$ layer. Layer preference is tested on the $4 \mathrm{~N}$ configuration. This is one of the most populated states in the kMC analysis of Ref.19. In addition, the high symmetry of this structure makes that only one 
configuration per doped layer is sufficient to this purpose. We find that 14 NTM elements out of 18 prefer top-surface, whereas three ( $\mathrm{Be}, \mathrm{Si}$ and $\mathrm{Te}$ ) prefer subsurface, and only one (Ga) prefers the $3^{\text {rd }}$ layer, consistent with the Ga-Fe bulk phase diagram, and is therefore not considered any more, although it might be reconsidered in future studies.

Criterion 2: $N_{2}$ ads-1. The largest prototypical barrier in Figure 1(c) corresponds to the free-

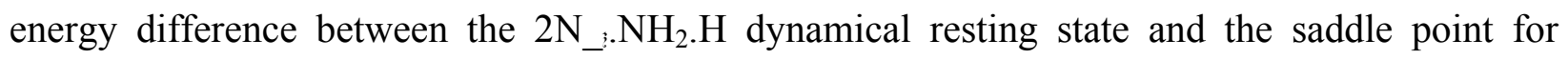
nitrogen $\left(\mathrm{N}_{2}\right)$ adsorption over the $2 \mathrm{~N}_{3}$; state $\left(2 \mathrm{~N}_{3} \rightarrow 2 \mathrm{~N}_{3} \cdot \mathrm{N} 2\right)$, see Figure 2. An improved catalyst should decrease this energy and therefore the free-energy of the $2 \mathrm{~N}_{3}$ s state, while still allowing $\mathrm{N}_{2}$ to bind to the surface and dissociate effectively. We translate this into the following estimated barrier and constraint:

$$
\begin{aligned}
& \text { Barrier(1) }=\Delta \mathrm{E}\left\{2 \mathrm{~N}_{-} \cdot \mathrm{NH}_{2} \cdot \mathrm{H} \rightarrow 2 \mathrm{~N}_{3}+\mathrm{NH}_{3}\right\}-0.102 \mathrm{eV} \\
& \text { Constraint: } \Delta \mathrm{E}\left\{2 \mathrm{~N}_{3} \cdot \mathrm{N}_{2}[\gamma] \rightarrow 2 \mathrm{~N}_{3}+\mathrm{N}_{2}\right\}>0.5 \mathrm{eV}
\end{aligned}
$$

where $2 \mathrm{~N}_{3} \cdot \mathrm{NH}_{2} \cdot \mathrm{H}, 2 \mathrm{~N}_{3}$, and $2 \mathrm{~N}_{3} \cdot \mathrm{N}_{2}[\gamma]$ are surface configurations shown in Figure 2 (just one possible configuration is illustrated in the figure for these states, but we examined all the possible ones). It should be emphasized that Barrier(1) can be decomposed into the sum of two terms, as shown by double arrows in Figure 1(c): (1) the free-energy paid by the system to go from the resting state $2 \mathrm{~N}_{3}$. $\mathrm{NH}_{2} . \mathrm{H}$ to the $2 \mathrm{~N}_{3}$; intermediate state; and (2) the $\mathrm{N}_{2}$ adsorption barrier from $2 \mathrm{~N}_{3}$ to the saddle point of $\mathrm{N}_{2}$ binding $\left(2 \mathrm{~N}_{3} \rightarrow 2 \mathrm{~N}_{3}: \mathrm{N}_{2}\right)$. Our results, listed in Table 1 , indicate that all the top-layer doping elements fail to pass this criterion. Note that As and Sb top-layer dopants repel the surface $\mathrm{N}$ into the subsurface, suggesting a strong repulsion interaction with $\mathrm{N}$ atoms which we interpret as failing to pass a stability criterion (highlighted in magenta in Figure 1). Considering subsurface doping elements, Be is excluded by this criterion, whereas $\mathrm{Si}$ and $\mathrm{Te}$ decrease Barrier(1). However, Te cannot pass Eqn. (2) suggesting that $\mathrm{N}_{2}$ cannot bind strongly to the Te-doped Fe surface. Thus, only Si passes Criterion 2 and will be further considered.

Table 1. The estimated free energy barrier (in eV) of Fe-bcc(111) doped systems from HHTCS $\left(673 \mathrm{~K}, 20 \mathrm{~atm}, \mathrm{P}\left(\mathrm{NH}_{3}\right)=1 \mathrm{~atm}\right)$. Criterion-2, $-3,-4$ and -5 represent the $\mathrm{N}_{2}$ adsorption to the dynamical resting state, the $\mathrm{N}_{2}$ adsorption to the $2 \mathrm{~N} \_2 \mathrm{H}$ state, the hydrogenation, and the $\mathrm{NH}_{3}$ desorption, respectively. The number in the bracket for criterion- 2 is the $\mathrm{N}_{2}$ binding energy to the $2 \mathrm{~N}$ surface, which is used to constrain the criterion-2. Compared to pure Fe, the free energy barriers of Si doped Fe catalyst are expected to be lower by $0.67 \mathrm{eV}, 0.27 \mathrm{eV}, 0.64 \mathrm{eV}$, and 0.05 $\mathrm{eV}$ for criterion-2, criterion-3, criterion-4, and criterion-5, respectively. The overall free barrier 
decreases by $0.3 \mathrm{eV}$ for $\mathrm{Si}$ doped $\mathrm{Fe}$ catalyst considering that the criterion- 2 is the rate determined step for pure Fe.

\begin{tabular}{|c|c|c|c|c|c|c|}
\hline Element & criterion-2 & criterion-3 & criterion-4 & criterion-5 & $\begin{array}{l}\text { Overall } \\
\text { barrier }(\mathrm{eV})\end{array}$ & $\begin{array}{l}\text { Estimated Rate } \\
\left(\sec ^{-1}, 673 \mathrm{~K}, 20\right. \\
\text { atm) }\end{array}$ \\
\hline \multicolumn{7}{|c|}{ Subsurface doping } \\
\hline $\mathbf{S i}$ & $1.01(0.85)$ & 1.29 & 0.89 & 1.38 & 1.38 & 649.03 \\
\hline $\mathrm{Be}$ & 1.76 & & & & & \\
\hline Te & $0.52(0.46)$ & & & & & \\
\hline \multicolumn{7}{|c|}{ Top-surface doping } \\
\hline Al & 1.83 & & & & & \\
\hline $\mathbf{B a}$ & 1.79 & & & & & \\
\hline $\mathbf{B i}$ & 2.08 & & & & & \\
\hline $\mathbf{C a}$ & 1.82 & & & & & \\
\hline Ge & 1.95 & & & & & \\
\hline In & 1.91 & & & & & \\
\hline $\mathrm{Mg}$ & 1.74 & & & & & \\
\hline $\mathbf{P}$ & 2.90 & & & & & \\
\hline $\mathbf{P b}$ & 1.95 & & & & & \\
\hline Sn & 2.04 & & & & & \\
\hline $\mathrm{Sr}$ & 1.80 & & & & & \\
\hline Tl & 2.00 & & & & & \\
\hline $\mathrm{Fe}$ & 1.68 & 1.56 & 1.53 & 1.43 & 1.68 & 3.68 \\
\hline
\end{tabular}

Criterion 3: $N_{2}$ ads-2. The second highest free-energy barrier in Figure 1(c) is connected with hydrogen poisoning, associated with the process: $2 \mathrm{~N}_{-} \rightarrow 2 \mathrm{~N}_{-}$. $2 \mathrm{H}$, i.e., the fact that $2 \mathrm{~N} \__{-} \cdot 2 \mathrm{H}$ may become the dynamical resting state. We translate this barrier into the formula:

$$
\operatorname{Barrier}(3)=\Delta \mathrm{E}\left\{2 \mathrm{~N} \__{-} \cdot 2 \mathrm{H} \rightarrow 2 \mathrm{~N}_{-} \text {? }+\mathrm{H}_{2}\right\}+0.113 \mathrm{eV}
$$

As shown in Table 1, Si can pass this criterion, and will be considered Si the following screening steps.

Criterion 4: hydrogenation. The third highest free-energy barrier in Figure 1(c) is related to hydrogenation of $\mathrm{NH}_{\mathrm{x}}$ to $\mathrm{NH}_{\mathrm{x}+1}$ species, which we model via the prototypical hydrogenation barrier from $2 \mathrm{~N}_{3} . \mathrm{NH}_{2} \cdot 2 \mathrm{H}$ to $2 \mathrm{~N}_{3}$. $\mathrm{NH}_{3} . \mathrm{H}$. Further, using a Brønsted-Evans-Polanyi relationship, we estimate this barrier as proportional to the energy difference between two configurations: $2 \mathrm{~N}_{-} \cdot \mathrm{NH}_{2} \cdot \mathrm{H}$ and $2 \mathrm{~N}_{3} \cdot \mathrm{NH}_{3} \cdot \mathrm{H}$, leading to the following formula: 


$$
\text { Barrier (4) }=\Delta \mathrm{E}\left\{2 \mathrm{~N}_{-}: \mathrm{NH}_{2} \cdot \mathrm{H}+\frac{1}{2} \mathrm{H}_{2} \rightarrow 2 \mathrm{~N}_{-}: \mathrm{NH}_{3} \cdot \mathrm{H}\right\}+1.549 \mathrm{eV}
$$

As shown in Table 1, Si dopant passes this criterion and will be examined in the final criterion 5.

Criterion 5: $\mathrm{NH}_{3}$ des. The last free energy barrier in Figure 1c is $\mathrm{NH}_{3}$ desorption from $2 \mathrm{~N}_{3} \cdot \mathrm{NH}_{3} \cdot \mathrm{H}$, and is estimated using the following formula:

$$
\begin{aligned}
& \text { Barrier }(5)=\Delta \mathrm{E}\left\{2 \mathrm{~N}_{-3} \cdot \mathrm{NH}_{2} \cdot \mathrm{H}+\frac{1}{2} \mathrm{H}_{2} \rightarrow 2 \mathrm{~N}_{-} \cdot \mathrm{NH}_{3} \cdot \mathrm{H}\right\}+\Delta \mathrm{H}\left\{2 \mathrm{~N}_{-}: \mathrm{NH}_{2} \cdot \mathrm{H} \rightarrow 2 \mathrm{~N}_{-} \cdot \mathrm{H}+\right. \\
& \left.\mathrm{NH}_{3}\right\}+0.355 \mathrm{eV}
\end{aligned}
$$

Si dopant passes this criterion, as shown in Table 1.

Thus, we identified Si as a promising dopant. In the HHTCS, we used the 4N configuration to test layer stability finding that Si subsurface doping is more stable with respect to top layer and $3^{\text {rd }}$ layer doping. In detail, Si prefers the subsurface site by $\sim 1.10 \mathrm{eV}$ with respect to top layer site and by $\sim 0.55 \mathrm{eV}$ than $3^{\text {rd }}$ layer site. This leads to expected populations of these competitive (nonsubsurface) sites by $6 \times 10^{-6} \%$ and $2 \times 10^{-2} \%$, respectively, at $500{ }^{\circ} \mathrm{C}$. The fact that the subsurface configuration is much more stable than other sites also suggests that the probability for the Si dopant to diffuse from the subsurface to the top surface or to the bulk ( $3^{\text {rd }}$ layer) is low. Therefore, we focus on the HB reaction mechanism only for Si doping the subsurface site. To further ensure that Si stays in the subsurface during the whole reaction process, we considered the layer stability for additional two states: $2 \mathrm{~N}_{3} .2 \mathrm{H}$ and $3 \mathrm{~N} . \mathrm{H}$ which are the most populated according to the following $\mathrm{kMC}$ analysis. Our simulation results indicate that the Si subsurface is at least $0.5 \mathrm{eV}$ more stable than the other two layers also for these highly populated states. Therefore, we expect that Si remains in the subsurface during the entire HB process.

Regarding catalyst degradation mechanisms, we focused on processes such as the competitive formation of $\mathrm{SiH}_{4}, \mathrm{SiH}_{3}\left(\mathrm{NH}_{2}\right), \mathrm{SiH}_{3} \mathrm{OH}$ and the consequent loss of $\mathrm{Si}$ from the Si-doped surface, and we calculated the reaction energy for this process as follows:

$$
\begin{aligned}
& \text { Si-doped-Fe_111(4N) }+1 / 2 \mathrm{Fe}(\text { bcc-unit cell })+2 \mathrm{H}_{2} \rightarrow \mathrm{Fe} \_111(4 \mathrm{~N})+\mathrm{SiH}_{4} \\
& \text { 2Si-doped-Fe_111(4N) }+\mathrm{Fe}(\text { bcc-unit cell })+\mathrm{N}_{2}+5 \mathrm{H}_{2} \rightarrow 2 \mathrm{Fe} \_111(4 \mathrm{~N})+2 \mathrm{SiH}_{3}\left(\mathrm{NH}_{2}\right) \\
& \text { 2Si-doped-Fe_111(4N) }+1 / 2 \mathrm{Fe}(\text { bcc-unit cell })+\mathrm{H}_{2} \mathrm{O}+\mathrm{H}_{2} \rightarrow 2 \mathrm{Fe}_{-} 111(4 \mathrm{~N})+2 \mathrm{SiH}_{3}(\mathrm{OH})
\end{aligned}
$$


At $0 \mathrm{~K}$, the reactions (6), (7) and (8) are endothermic by 2.73, 1.40 and $1.38 \mathrm{eV}$ at QM level, demonstrating that formation of these molecules from Si-doped Fe(111) surface is unlikely. The phase diagram of $\mathrm{Si}-\mathrm{Fe}^{42}$ suggests that $\sim 10 \% \mathrm{Si}$ can be incorporated into bec $\mathrm{Fe}$ at $\mathrm{HB}$ conditions. This indicates that our model $(23 \mathrm{Fe}+1 \mathrm{Si})$ is largely compatible with experimental information on bulk phases.

\subsection{Reaction mechanism of HB process on Si-doped Fe(111) surface and full energy diagram}

The above in silico analysis suggests that the Si-doped Fe catalyst can significantly improve the reaction by decreasing the overall barrier from $1.68 \mathrm{eV}$ to $1.38 \mathrm{eV}$. Estimating the TOF using the transition-state-theory $(\mathrm{TST})$ as: rate $=\left(\mathrm{k}_{\mathrm{B}} \mathrm{T} / \mathrm{h}\right) \times \exp \left[-\Delta \mathrm{G}^{\dagger}{ }_{\text {overall }} / \mathrm{k}_{\mathrm{B}} \mathrm{T}\right]$ (where $\Delta \mathrm{G}^{\dagger}{ }_{\text {overall }}$ is the overall free-energy barrier, $T$ is the temperature, $k_{B}$ is the Boltzmann constant, and $h$ is the Planck constant), we expect that the reaction rate can be increased from $3.68 \mathrm{NH}_{3} / \mathrm{sec} /(2 \times 2)$ to $649.03 \mathrm{NH}_{3} / \mathrm{sec}$ at $400{ }^{\circ} \mathrm{C}$ and 20 atm, a 176-fold improvement exceeding that of previously identified dopants. ${ }^{26-28}$ However, a number of assumptions were used in HHTCS screening: (1) thermal corrections are not affected by dopants; (2) the Brønsted-Evans-Polanyi relationships apply in hydrogenation steps; and (3) the overall reaction scheme is not affected by dopants. To validate the HHTCS predictions, we reconstructed the complete free-energy diagram of Si-doped $\mathrm{Fe}(111)$ surface, and used it in $\mathrm{kMC}$ simulations to predict HB kinetics under realistic conditions to compare to pure Fe catalyst.

We performed QM simulations on a (2x2) Fe-bcc(111) surface model substitutionally doped with one Si atom subsurface. Figure 3 displays a simplified reaction pathway with the most

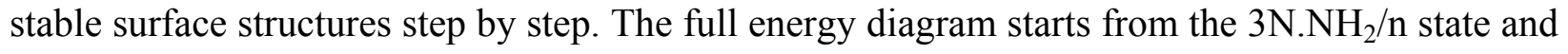
then transforms to $3 \mathrm{~N} . \mathrm{NH}_{2} / \mathrm{n}$. H by dissociating $\mathrm{H}_{2}$ gas and one $\mathrm{H}$ is bonded to the surface. Then

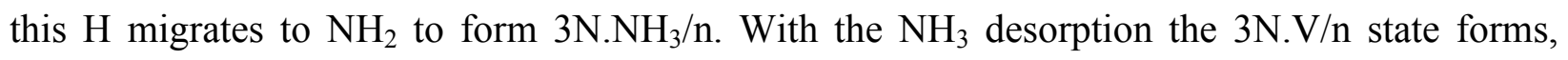
followed by the $2^{\text {nd }} \mathrm{H}$ bonded to the surface to form $3 \mathrm{~N}$.V/n.H. Next, the $\mathrm{H}$ migrates to form $2 \mathrm{~N}_{3}$. V.NH_b and it transforms to $2 \mathrm{~N}_{3} . \mathrm{NH} .2 \mathrm{H}_{-} \mathrm{c}$ with one $\mathrm{H}_{2}$ molecule dissociated into the surface. With two consequent hydrogenation steps, the $2 \mathrm{~N}_{-}$. $\mathrm{NH}_{3}$ b configuration forms. As the desorption of the $2^{\text {nd }} \mathrm{NH}_{3}$ molecule, the $2 \mathrm{~N}_{3} .2 \mathrm{~V} \_$b state forms. Next the $\mathrm{N}_{2}$ molecule starts to bond to the surface and dissociated into two $\mathrm{N}$ to form $4 \mathrm{~N}$ configurations. The details of $\mathrm{N}_{2}$ dissociation could be found in Figure S3 of SI. With the next two hydrogenation steps, the 4N state goes back to $3 \mathrm{~N}$. $\mathrm{NH}_{2} / \mathrm{n}$ state. The mechanistic reaction path on the Si-doped Fe system is 
similar to that on the pure $\mathrm{Fe}$ surface ${ }^{19}$ and Ni-doped surface (see references for detailed discussion). ${ }^{28}$ Figure 4 then plots the standard state free energy diagram of Si-doped Fe(111) system. It should be stressed that the dynamical resting states at $400{ }^{\circ} \mathrm{C}$ and $20 \mathrm{~atm}$ are the $3 \mathrm{~N}_{-} \mathrm{NH}_{3}$ and $2 \mathrm{~N} \_$. $2 \mathrm{H}$ configurations, lower by $0.14-0.16 \mathrm{eV}$ with respect to $2 \mathrm{~N}_{-}$: $\mathrm{NH}_{2} \cdot \mathrm{H}$ which is the resting state for pure iron. Hydrogen and ammonia poisoning thus play a crucial role, and, as we will see below, they damp the HHTCS-expected rate improvement of the Si-doped Fe system. This proves that the dopants can influence the rate determining steps in complex reaction paths such as that of HB process. Therefore, it is essential to use our HHTCS approach, considering all the potential important RDSs, to such complex HB reaction.
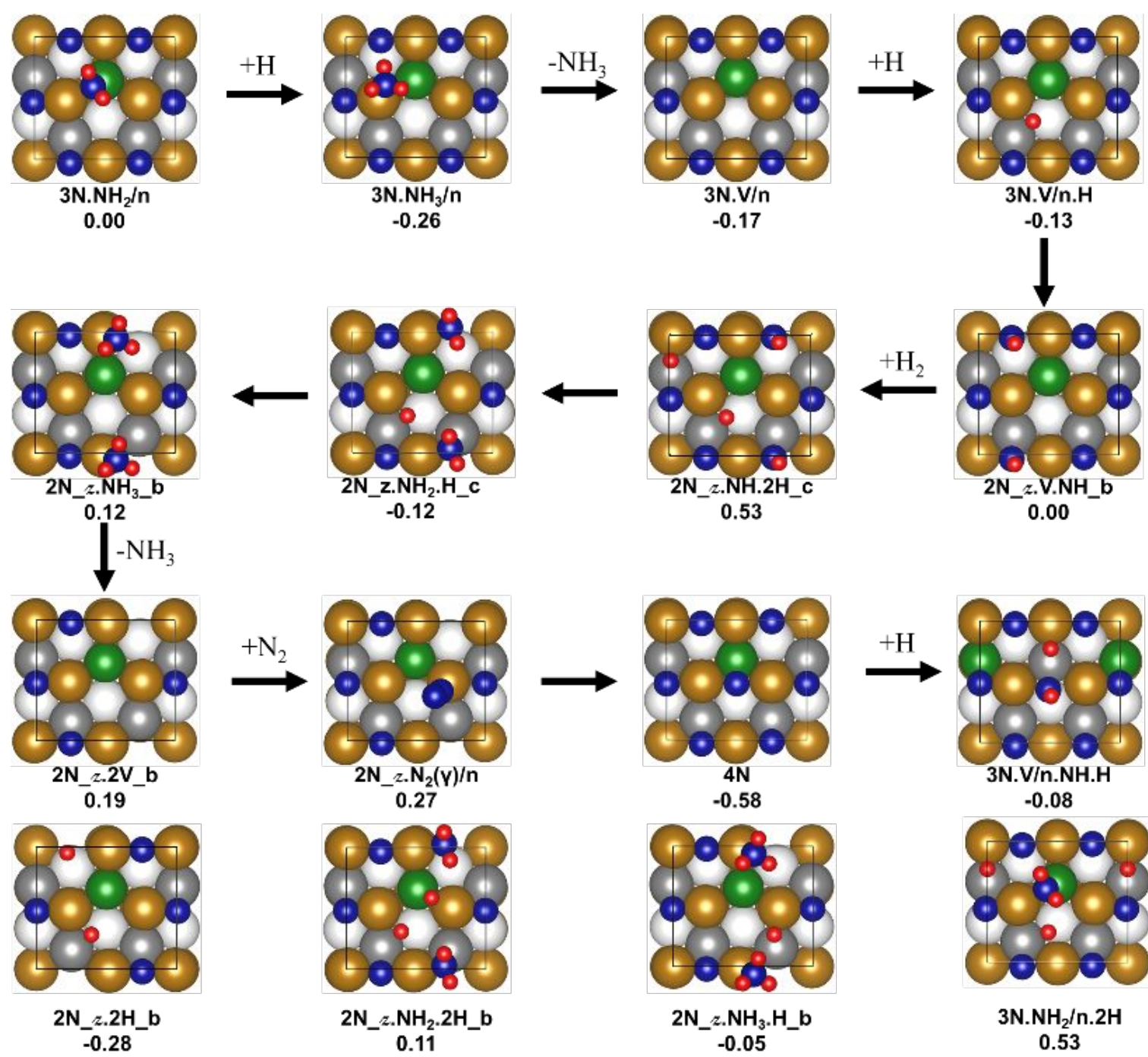
Figure 3 The step-by-step reaction process for $\mathrm{NH}_{3}$ synthesis on sublayer Si doped Fe-bcc(111). Four possible doping sites are considered in the full reaction path and only the most plausible configurations are shown. The $\mathrm{N}_{2}$ dissociation steps is displayed in Figure S3 of SI. Free energies are in $\mathrm{eV}$ at conditions of $\mathrm{T}=673 \mathrm{~K}$ and $\mathrm{P}_{-} \mathrm{H}_{2}=15 \mathrm{~atm}, \mathrm{P}_{-} \mathrm{N}_{2}=5 \mathrm{~atm}$, and $\mathrm{P}_{-} \mathrm{NH}_{3}=1$ atm. The letters $\mathrm{a}, \mathrm{b}$, and c represent the doped element is in vertically in line with respect to the nitrogen, vacancy, and hydrogen, respectively. The letters $\mathrm{n}$ indicates that the doped element is near to the species. The $\mathrm{Si}, \mathrm{N}$ and $\mathrm{H}$ atoms are represented by green, blue and red balls, respectively.

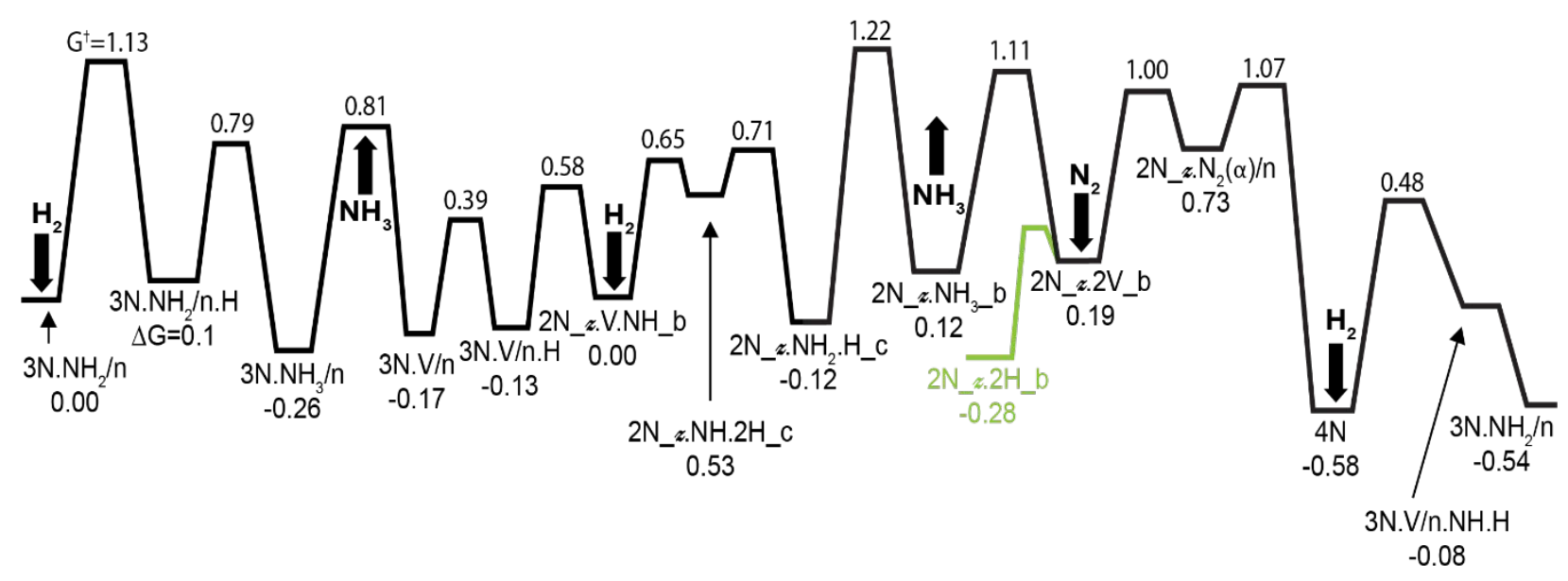

Figure 4 The standard state free energy landscape for $\mathrm{NH}_{3}$ synthesis reactions on $\mathrm{Si}$-doped Febcc(111) subsurface under $673 \mathrm{~K}$ and 20 atm conditions $\left(\mathrm{P}\left(\mathrm{NH}_{3}\right)=1 \mathrm{~atm}\right)$. The energy state $3 \mathrm{~N}_{-} \mathrm{NH}_{2}$ is taken as the reference, ${ }^{19}$ with a free energy of zero. The green $2 \mathrm{~N}$ _. $2 \mathrm{H}$ state illustrates the mechanism of hydrogen poisoning.

\section{3 kMC simulations of HB kinetics}

We use kinetic Monte Carlo (kMC) modeling based on the QM reaction network and energetics derived above and in previous work ${ }^{19,26}$ to predict reaction kinetics of pure and Sidoped Fe-bcc(111) under steady-state conditions. As in ref 19, kMC rate constants were evaluated using transition state theory (TST) and QM free-energy barriers (gas-phase adsorption was modeled via the reverse desorption combined with the microscopic reversibility principle), and we used $20 \mathrm{kMC}$ independent replicas and $2 \times 10^{10} \mathrm{kMC}$ steps in each replica, corresponding to $\sim 20$ minutes of real time. We took as a reference the pure Fe-bcc(111) catalyst at $\mathrm{P}\left(\mathrm{H}_{2}\right)=150$ atm, $\mathrm{P}\left(\mathrm{N}_{2}\right)=50 \mathrm{~atm}, \mathrm{P}\left(\mathrm{NH}_{3}\right)=1 \mathrm{~atm}$, and $\mathrm{T}=773{ }^{\circ} \mathrm{K}$, which are typical operating conditions of industrial HB process, and we investigated how much we could decrease temperature and/or pressure while keeping about the same $\mathrm{HB}$ reaction rate of $835 \mathrm{NH}_{3}$-molecules/sec per $(2 \times 2)$ 
surface site. Representative results are reported in Table 2, where we report TOF together with per-cent populations (i.e., per-cent residence times) of all configurations with populations $>1 \%$. Notably, $\mathrm{Fe}_{4} / / \mathrm{Fe}_{3} \mathrm{Si}(111)$ achieves a TOF of $811 \mathrm{NH}_{3} / \mathrm{s} /(2 \times 2)$ at $\mathrm{P}\left(\mathrm{H}_{2}\right)=43$ atm, $\mathrm{P}\left(\mathrm{N}_{2}\right)=17$ atm, $\mathrm{P}\left(\mathrm{NH}_{3}\right)=1$ atm and $\mathrm{T}=673^{\circ} \mathrm{K}$, or a TOF of $727 \mathrm{NH}_{3} / \mathrm{s} /(2 \times 2)$ at $\mathrm{P}\left(\mathrm{H}_{2}\right)=15 \mathrm{~atm}, \mathrm{P}\left(\mathrm{N}_{2}\right)=5 \mathrm{~atm}$, $\mathrm{P}\left(\mathrm{NH}_{3}\right)=1$ atm and $\mathrm{T}=773^{\circ} \mathrm{K}$. In other words, the Si-doped catalyst achieves essentially the same HB performances of the pure Fe industrial catalyst, however, at a temperature decreased by $100{ }^{\circ} \mathrm{K}$ and a reactant pressure decreased by a factor of 3 or alternatively by keeping the same high temperature but decreasing the pressure by a factor of 10 . Note that we take advantage of hydrogen poisoning to reduce the $\mathrm{H}_{2}$ pressure to a slightly under-stoichiometric value at $673 \mathrm{~K}$. It should be stressed that $\mathrm{Fe}_{4} / / \mathrm{Fe}_{3} \mathrm{Si}-\mathrm{bcc}(111)$ is still quite active even at relatively low pressures, achieving a respectable $\mathrm{HB}$ rate of $194 \mathrm{NH}_{3} / \mathrm{s} /(2 \times 2)$ vs. $4.5 \mathrm{NH}_{3} / \mathrm{s} /(2 \times 2)$ for the pure-Fe catalyst $\left(\mathrm{P}_{\mathrm{H} 2}=15, \mathrm{P}_{\mathrm{N} 2}=5, \mathrm{P}_{\mathrm{NH} 3}=1\right.$ atm, $\left.\mathrm{T}=673^{\circ} \mathrm{K}\right)$, i.e., a 43-fold increase (4-times smaller than the expected increase due to the fact that HHTCS underestimates the hydrogen poisoning effect and assume the same dynamical resting state, but $\sim 3$-times larger than the previously identified $\mathrm{Ni}$ dopant $\left.^{28}\right)$. Finally, we note that under the $\mathrm{HB}$ industrial conditions of $\left(\mathrm{P}_{\mathrm{H} 2}=150, \mathrm{P}_{\mathrm{N} 2}=50, \mathrm{P}_{\mathrm{NH} 3}\right.$ $\left.=1 \mathrm{~atm}, \mathrm{~T}=773{ }^{\circ} \mathrm{K}\right), \mathrm{Fe}_{4} / / \mathrm{Fe}_{3} \mathrm{Si}-\mathrm{bcc}(111)$ reaches a production rate of $11130 \mathrm{NH}_{3} / \mathrm{s} /(2 \times 2)$, over 13-fold larger than that of pure Fe, implying that one could correspondingly reduce production costs by more than an order of magnitude even maintaining the present HB plants.

As shown by the results of Table 2, the reason why Si-subsurface doping accelerates the HB reaction rate is basically connected with the decrease in the largest primary barrier, associated with the free-energy cost of adsorbing/dissociating $\mathrm{N}_{2}$, without increasing the other barriers. In other words, Si-doping stabilizes the $2 \mathrm{~N}_{3}$ : configuration with respect to a full-coverage catalyst surface. In the next section we rationalize this effect via an analysis of chemical bonding.

A more detailed analysis brings further insight. The populations $\left(\mathrm{P}_{\mathrm{i}}\right)$ of the states ' $\mathrm{i}$ ' in Table 2 can be expressed as apparent free-energy differences $\Delta \mathrm{G}_{\mathrm{i}}^{\text {apparent }}=-\ln \left(\mathrm{P}_{\mathrm{i}} / \mathrm{P}_{0}\right)$, with $\mathrm{P}_{0}$ the population of the reference state $3 \mathrm{~N} . \mathrm{NH}_{2} / \mathrm{n}$. These $\Delta \mathrm{G}_{\mathrm{i}}$ apparent correlate with the corresponding thermodynamic free-energy differences $\Delta \mathrm{G}_{\mathrm{i}}$ (i.e., the populations of the states before the ratedetermining step are not far from equilibrium Boltzmann distributions), with both apparent and thermodynamic $\Delta \mathrm{G}_{\mathrm{i}}$ 's changing as functions of the given experimental conditions (see e.g. Figure 4 and Table 2 in Ref.19). Moreover, by singling out the states realizing a deep minimum 
in the free-energy diagram, the reaction path can be partitioned into successive sections, and the overall kinetics expressed as a series of consecutive simplified reaction steps (see the section "Kinetic analysis" and Figure 5 in Ref.20). The reaction free-energy diagram in Figure 4 at 673 $\mathrm{K},(15,5,1) \mathrm{atm}$ pressures can then be partitioned as illustrated in Figure S4a, with two main section defined by two dynamical resting states $\left(3 \mathrm{~N} \cdot \mathrm{NH}_{3} / \mathrm{n}\right.$ and $\left.2 \mathrm{~N} \_\mathrm{z} .2 \mathrm{H} \_\mathrm{b}\right)$ and two corresponding dynamical saddle points (hydrogenation of $2 \mathrm{~N} \_\mathrm{z} . \mathrm{NH}_{2} \cdot \mathrm{H} \_\mathrm{c}$ and $\mathrm{N}_{2}$ adsorption onto $2 \mathrm{~N} \_$z.2H_b, respectively), with the free-energy barrier of the first section $(1.48 \mathrm{eV})$ larger than the one in the second section $(1.39 \mathrm{eV})$ and therefore dominating. By increasing pressures to $(47,17,1)$ atm, however, the diagram changes as illustrated in Figure S4b: the 2N_z.NH $\mathrm{NH}_{2}$ _c states lowers with respect to $3 \mathrm{~N} . \mathrm{NH}_{3} / \mathrm{n}$, and becomes a secondary dynamical resting state of the first section of the diagram, and the free-energy barrier of the first section also lowers to $1.38 \mathrm{eV}$ thus becoming comparable with the barrier of the second section. This accurately reflects in the populations, with the sum of the $3 \mathrm{~N} . \mathrm{NH}_{3} / \mathrm{n}$ and $2 \mathrm{~N} \_z . \mathrm{NH}_{2} \cdot \mathrm{H} \_$c populations comparable to that of $2 \mathrm{~N} \_z .2 \mathrm{H} \_$b, together making $80 \%$ of the total. Also, the "control" pure Fe free-energy diagram under industrial HB conditions can be simplified into a two-step process, as illustrated in Figure $\mathrm{S} 4 \mathrm{c}$, and this translates to a $\mathrm{kMC}$ modeling with multi-dynamical-resting-state populations in Table 2: $2 \mathrm{~N}_{3} . \mathrm{NH}_{2} . \mathrm{H}_{-} \mathrm{c}, 2 \mathrm{~N}_{3} .2 \mathrm{H}_{-} \mathrm{b}$ and $2 \mathrm{~N}_{-}$. $2 \mathrm{H}_{-} \mathrm{b}$. In comparison, the reaction free-energy diagram of the Si-doped $\mathrm{Fe}(111)$ surface catalyst at $773 \mathrm{~K}$ and $(15,5,1)$ atm pressures is much simpler, with basically only one dynamical resting state $3 \mathrm{~N} . \mathrm{V} / \mathrm{n}$, as illustrated schematically in Figure $\mathrm{S} 4 \mathrm{~d}$, and this is reflected in the dominant population of the $3 \mathrm{~N}$.V/n state in Table 2 .

Table 2. Reaction rates and percent populations $P_{i}$ (i.e., residence times) $=t_{i}(\%)$ for the most relevant configurations in $(2 \times 2)$ unit cells of pure and Si-doped $\mathrm{Fe}(111)$ surfaces under steadystate of ammonia synthesis as predicted by kMC simulations under different conditions. $\mathrm{H}_{2}, \mathrm{~N}_{2}$, $\mathrm{NH}_{3}$ pressures in atm. Note that the dynamical resting states are significantly affected by the temperature and pressure. ${ }^{20}$ The (i) $2 \mathrm{~N}_{\text {f }} .2 \mathrm{H}$, (ii) $2 \mathrm{~N}_{3} .2 \mathrm{H}$, and (iii) $3 \mathrm{~N}$ states are the 3 dynamical resting states under the 3 different conditions of: (i) $773 \mathrm{~K}$ and $200 \mathrm{~atm}$, (ii) $673 \mathrm{~K}$ and $54 \mathrm{~atm}$, and (iii) $773 \mathrm{~K}$ and $20 \mathrm{~atm}$, respectively. $\mathrm{P}\left(\mathrm{NH}_{3}\right)=1 \mathrm{~atm}$ in all cases.

\begin{tabular}{|l|c|c|c|c|}
\hline & $\mathrm{T}=773 \mathrm{~K}$ & & $\mathrm{~T}=673 \mathrm{~K}$ & $\mathrm{~T}=773 \mathrm{~K}$ \\
& $\mathrm{p}\left(\mathrm{H}_{2}, \mathrm{~N}_{2}, \mathrm{NH}_{3}\right)=($ & & $\mathrm{p}\left(\mathrm{H}_{2}, \mathrm{~N}_{2}, \mathrm{NH}_{3}\right)=$ & $\mathrm{p}\left(\mathrm{H}_{2}, \mathrm{~N}_{2}, \mathrm{NH}_{3}\right)=$ \\
& $150,50,1)$ & & $(47,17,1)$ & $(15,5,1)$ \\
& $\mathbf{F e}(\mathbf{1 1 1})$ & & $\mathbf{F e} 4 / / \mathbf{F e}_{3} \operatorname{Si}(\mathbf{1 1 1})$ & $\mathbf{F e} 4 / \mathbf{F e} \mathbf{e}_{3} \operatorname{Si}(\mathbf{1 1 1})$ \\
\hline configuration & $\mathrm{P}_{\mathrm{i}}=\mathrm{t}_{\mathrm{i}}(\%)$ & configuration & $\mathrm{P}_{\mathrm{i}}=\mathrm{t}_{\mathrm{i}}(\mathbf{\%})$ & $\mathrm{P}_{\mathrm{i}}=\mathrm{t}_{\mathrm{i}}(\mathbf{0})$ \\
\hline
\end{tabular}




\begin{tabular}{|c|c|c|c|c|}
\hline $3 \mathrm{~N}^{-\mathrm{NH}_{2}}$ & 3.7 & $3 \mathrm{~N}^{-\mathrm{NH}_{3}}$ & 24.2 & 0.6 \\
\hline $3 \mathrm{~N} . \mathrm{H}$ & 3.2 & $3 \mathrm{~N}$ & 5.1 & 78.8 \\
\hline $2 \mathrm{~N}_{-} \cdot \mathrm{NH}_{2} \cdot \mathrm{H}$ & 32.3 & $3 \mathrm{~N} . \mathrm{H} / 2 \mathrm{~N}_{-}: \mathrm{NH}$ & 8.0 & 13.4 \\
\hline $2 \mathrm{~N}_{3}: \mathrm{NH}_{2} \cdot 2 \mathrm{H}$ & 3.9 & $2 \mathrm{~N}_{-}: \mathrm{NH}_{2} \cdot \mathrm{H}$ & 18.6 & 1.0 \\
\hline $2 \mathrm{~N} \_.2 \mathrm{H}$ & 43.6 & $2 \mathrm{~N}_{3} \cdot \mathrm{H}$ & 1.3 & 1.0 \\
\hline $2 \mathrm{~N}_{3} .2 \mathrm{H}$ & 12.6 & $2 \mathrm{~N}_{-} \mathrm{t} .2 \mathrm{H}$ & 2.1 & 0.2 \\
\hline $4 \mathrm{~N}$ & 0.6 & $2 \mathrm{~N}_{3} .2 \mathrm{H}$ & 40.1 & 3.6 \\
\hline $\begin{array}{c}\text { TOF from kMC } \\
\mathrm{NH}_{3} \\
\mathrm{~mol} / \mathrm{s} /(2 \times 2)\end{array}$ & 835 & $\begin{array}{c}\text { TOF from } \mathrm{kMC} \\
\mathrm{NH}_{3} \\
\mathrm{~mol} / \mathrm{s} /(2 \mathrm{x} 2)\end{array}$ & 811 & 727 \\
\hline
\end{tabular}

\subsection{Chemical insight into Si doping: spin analysis}

To gain insight on the reason why Si has such a beneficial effect on HB rate, we analyze the atomic charges and spins of selected configurations. Specifically, we focus on $4 \mathrm{~N}, 3 \mathrm{~N}$ and $2 \mathrm{~N} \_$? states, see Figure 5, to illustrate the effect of progressively "de-nitrogenating" the $\mathrm{Fe}(111)$ surface. We use a valence-bond analysis scheme ${ }^{19,43}$ to monitor bonding between metal surface and adsorbed species, according to the criterion that metal/adsorbate covalent bonds decrease the spin on the metal surface, with each covalent bond decreasing the spin by $1 \mu_{\mathrm{B}}$ unit. The most striking result of this analysis is the $1 \mu_{\mathrm{B}}$ difference in magnetization between top-layer and subsurface $\mathrm{Fe}$ atoms in the $4 \mathrm{~N}$ configuration of the pure Fe system (top row in Figure 5): $\approx 2.5$ vs. $\approx 1.5 \mu_{\mathrm{B}}$, respectively. This difference is only due to the presence of $\mathrm{N}$ atoms adsorbed in bridge sites directly bound to the subsurface Fe atoms, as proved by the fact that subsurface Fe atoms recover a magnetization of $\approx 2.5 \mu_{\mathrm{B}}$ when the $\mathrm{N}$ atoms bound to them are progressively removed in going from the $4 \mathrm{~N}$ to the $3 \mathrm{~N}$ and $2 \mathrm{~N}_{-}$c configurations. This proves that $\mathrm{N}$ in bridge sites is covalently bound to subsurface metal atoms. In contrast, we do not find a difference in the magnetization of the Si dopant in the three $4 \mathrm{~N}, 3 \mathrm{~N}$, and $2 \mathrm{~N}_{-}$c configurations, in which Si keeps a constant and modest $\left(\approx-0.1 \mu_{\mathrm{B}}\right)$ spin. We can thus understand that Si subsurface improves HB 
reaction rate by decreasing the bonding of the $\mathrm{N}$ adatom next to it, hence stabilizing the $2 \mathrm{~N}$ ? with respect to the $4 \mathrm{~N}$ state, with a correspondent decrease in Barrier(1) or " $\mathrm{N}_{2}$ ads-1" as discussed above, without destabilizing the $\mathrm{C} 7$ site which is important for dissociating the N-N bond after $\mathrm{N}_{2}$ adsorption onto the $2 \mathrm{~N} \_$state. ${ }^{21}$ However, the effect of subsurface Si on $\mathrm{H}$ and $\mathrm{NH}_{3}$ adsorption is smaller, because the hydrogen atom has a weaker covalent bond to subsurface $\mathrm{Fe}$, while $\mathrm{NH}_{3}$ absorbs on a top site which is nearly unaffected by subsurface neighbors. This then explains why Si-doping suffers from hydrogen and ammonia poisoning, as shown by the free-energy diagram of Figure 4 and the kMC simulation results. To further improve HB catalytic efficiency, one could explore doping with more than one element, i.e., using multiple dopants. The HHTCS approach can be straightforwardly applied to searching for multiple dopants, by properly adjusting the screening criteria. This will the subject of future studies..
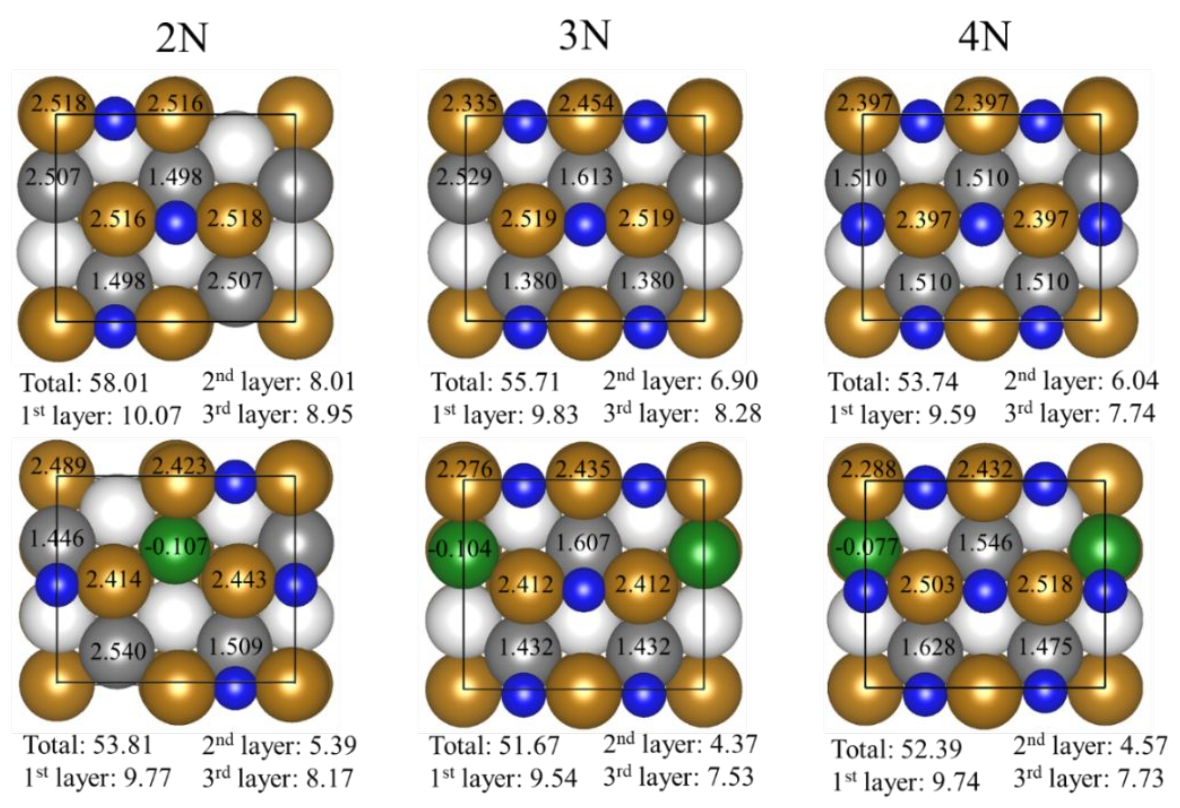

Figure 5. The magnetization of the $\mathrm{Si}$ atom and the $\mathrm{Fe}$ atoms around it are shown on the pure and Si-doped Fe-bcc(111) surface to show how Si influences the magnetization due to spin-spin bonding. The total spin difference between $2 \mathrm{~N}$ and $4 \mathrm{~N}$ state is significantly decreased due to the Si-doping, suggesting that the energy between $2 \mathrm{~N}$ and $4 \mathrm{~N}$ significantly decreases, explaining that the $2 \mathrm{~N}$ state is much lower in Si-doped system than pure Fe. The total spin of $3 \mathrm{~N}$ in Si-doped system is even lower than $4 \mathrm{~N}$ state, explaining the significant energy decrease of $3 \mathrm{~N}$ state due to the Si-doping.

\subsection{K-promoter effects on pure Fe and Si-doped Fe systems}


Experiments on model but realistic single-crystal surfaces ${ }^{21}$ show that the addition of potassium promoter increases the TOF by a factor of 2 on the most active Fe bcc surfaces, a significant increase but much smaller than the enhancement we predict for Si-doped catalysts. We conducted exploratory simulations (reported in the SI, Table S1 and Figure S5) of the Kpromoter effect for the pure Fe catalyst which suggest an enhancement by a factor of 5 compared to a factor of 2 for experiment. In this simple model $\mathrm{K}$ doping did not have a beneficial effect on the Si-doped catalyst.

The Si-doped system exhibits much better improvement on the TOF compared to previous screened elements $\mathrm{Rh}, \mathrm{Co}, \mathrm{Ni}$, etc. This arises from the crucial role of subsurface atoms in binding nitrogen species, lowering the energy of $2 \mathrm{~N}$ state significantly in the Si-doped system with respect to pure Fe and other doped systems. The improvement on the TOF is also much better than the potassium promoter which increases the TOF by a factor of 2 on the most active Fe bcc surfaces..$^{21}$

\section{CONCLUSION}

In summary, we have applied a reaction mechanism based HHTCS to identify a very promising non-metal element, $\mathrm{Si}$, as the dopant in the industry-used Fe catalysts to significantly enhance the TOF by 13 -fold at HB typical industrial conditions and $\sim 43$-fold under ideal HB conditions. The HHTCS assumption that the dopant does not affect the overall reaction network is essentially validated in the present case of $\mathrm{HB}$ over Fe-based catalysts. However, the dopants may change the RDS in such complex reaction pathway. The microkinetic analysis using kMC model predicts that the Fe-Si binary catalyst can decrease the harsh industry conditions of $200 \mathrm{~atm} / 773$ $\mathrm{K}$ to much milder conditions of $20 \mathrm{~atm} / 773 \mathrm{~K}$ or $50 \mathrm{~atm} / 673 \mathrm{~K}$. This suggests that faster rates in $\mathrm{HB}$ can be carried out at much less extreme conditions of pressure and temperature while maintaining the same TOF as current HB processes. The valence-bond analysis on both the Sidoped and undoped Fe-bcc(111) surface indicates that the doped Si significantly decrease the spin difference between $2 \mathrm{~N}$ and $4 \mathrm{~N}$ state, stabilizing the $2 \mathrm{~N}$ state and leading the decreased barrier compared to pure Fe.

\section{ASSOCIATED CONTENT}

Supplemental Information 
The Supporting Information (SI) is available free of charge on the ACS Publications website at DOI:xxx. The SI includes (1) The partitioned free energy diagram of $\mathrm{NH}_{3}$ synthesis on $\mathrm{Fe}(111)$ surface; (2) The nomenclature of possible configurations with at most 3 absorbates on the surface; (3) The N2 dissociation path on Fe-Si (111) surface; (4) The partitioned free energy diagram of Si-doped F(111) and Fe(111) systems at various conditions; (5) The K-Promoter effects on catalytic performance; and (5) the Xlsx files containing the raw DFT data for HHTCS and the raw data for reaction energy path of HB process on Fe-Si surface.AUTHOR

INFORMATION

\section{Corresponding Authors}

*qia@unr.edu , alessandro.fortunelli@,cnr.it, wag@,caltech.edu

\section{ORCID:}

Qi An: 0000-0003-4838-6232

Alessandro Fortunelli: 0000-0001-5337-4450

William A. Goddard, III: 0000-0003-0097-5716

Notes

The authors declare no competing financial interest.

\section{ACKNOWLEDGMENTS}

Q.A. was supported by the U.S. Nuclear Regulatory Commission (NRC) under Grant No. NRCHQ-84-15-G-0028. M.M. was supported by NSF (CMMI-1727428). A.F. gratefully acknowledges the contribution of the International Research Network IRN on Nanoalloys (CNRS).

\section{REFERENCES}

(1) Appl, M. Ammonia, ullmann's encyclopedia of industrial chemistry; Wiley-VCH: Weinheim; 2006.

(2) Mittasch, A.; Frankenburg, W. Early studies of multicomponent catalysts. Adv. Catal. 1950, 2, 81-104.

(3) Nielsen, A. Ammonia: catalysis and manufacture; Springer: Heidelberg; 1995.

(4) Jennings, J. R. Catalytic ammonia synthesis: fundamentals and practice; Plenum Press: New York; 1991. 
(5) Kitano, M.; Kanbara, S.; Inoue, Y.; Kuganathan, N.; Sushko, P. V.; Yokoyama, T.; Hara, M.; Hosono, H. Electride support boosts nitrogen dissociation over ruthenium catalyst and shifts the bottleneck in ammonia synthesis. Nat. Commun. 2015, 6, 6731.

(6) Tsai, M. C.; Seip, U.; Bassignana, I. C.; Kuppers, J.; Ertl G. A vibrational spectroscopy study on the interaction of $\mathrm{N}_{2}$ with clean and K-promoted Fe(111) surfaces: $\pi$-bonded dinitrogen as precursor for dissociation. Surf. Sci. 1985, 155, 387-399.

(7) Ertl, G. Reactions at surfaces: from atoms to complexity (Nobel Lecture). Angew. Chem. Int. Ed. Engl. 2008, 47, 3524-3535

(8) Aika, K.; Ozaki, A.; Hori, H. Activation of nitrogen by alkali-metal promoted transitionmetal.1. Ammonia synthesis over ruthenium promoted by alkali-metal. J. Catal. 1972, 27, 424-431.

(9) Ozaki A. Development of alkali-promoted ruthenium as a novel catalyst for ammoniasynthesis. Acc. Chem. Res. 1981, 14, 16-21.

(10) Bielawa, H.; Hinrichsen, O.; Birkner, A.; Muhler, M. The ammonia-synthesis catalyst of the next generation: barium-promoted oxide-supported ruthenium. Angew. Chem. Int. Ed. Engl. 2001, 40, 1061-1063.

(11) Kandemir, T.; Schuster, M. E.; Senyshyn, A.; Behrens, M.; Robert Schlögl, R. The Haber-Bosch process revisited: on the real structure and stability of "ammonia iron" under working conditions. Angew. Chem. Int. Ed. 2013, 52, 12723 -12726.

(12) Valera-Medina, A.; Xiao, H.; Owen-Jones, M.; David, W. I. F.; Bowen, P. J. Ammonia for power. Prog. Energy Combust. Sci. 2018, 69, 63-102.

(13) Chen, J. G.; Crooks, R. M.; Seefeldt, L. C.; Bren, K. L.; Bullock, R. M.; Darensbourg, M. Y.; Holland, P. L.; Hoffman, B.; Janik, M. J.; Jones, A. K.; Kanatzidis, M. K.; King, P.; Lancaster, K. M.; Lymar, S. V.; Pfromm, P.; Schneider, W. F.; Schrock, R. R. Beyond fossil fuel-driven nitrogen transformations. Science 2018, 360, 873.

(14) Yiokari, C. G.; Pitselis, G. E.; Polydoros, D. G.; Katsaounis, A. D.; Vayenas, C. G. High pressure electrochemical promotion of ammonia synthesis over an industrial iron catalyst. J. Phys. Chem. A 2000, 104, 10600-10602.

(15) Zhou, F.; Azofra, L. M.; Ali, M.; Kar, M.; Simonov, A. N.; McDonnell-Worth, C.; Sun, C.; Zhang, X.; MacFarlane, D. R. Electro-synthesis of ammonia from nitrogen at ambient temperature and pressure in ionic liquids. Energy Environ. Sci. 2017, 10, 2516-2520.

(16) Ogura, K.; Takagi, M. The photoelectrochemical conversion of nitric oxide into ammonia at P-gallium arsenide in the presence of transition metal Ions and their complexes. J. Electroanal. Chem. Interfacial Electrochem. 1985, 183, 277-284.

(17) Furuya, N.; Yoshiba, H. Electroreduction of nitrogen to ammonia on gasdiffusion electrodes loaded with inorganic catalyst. J. Electroanal. Chem. Interfacial Electrochem. 1990, 291, 269-272.

(18) Sun, S. M.; An, Q.; Wang, W. Z.; Zhang, L.; Liu, J. J.; Goddard III, W. A. Efficient photocatalytic reduction of dinitrogen to ammonia on bismuth monoxide quantum dots. J. Mater. Chem. A 2017, 5, 201-209.

(19) Qian, J.; An, Q.; Fortunelli, A.; Nielsen, R. J.; Goddard III, W. A. Reaction mechanism and kinetics for ammonia synthesis on the Fe(111) surface. J. Am. Chem. Soc. 2018, 140, 6288-6297. 
(20) Fuller, J.; Fortunelli, A.; Goddard III, W. A.; An, Q. Reaction mechanism and kinetics for ammonia synthesis on the Fe (211) reconstructed surface. Phys. Chem. Chem. Phys. 2019, 21, 11444-11454.

(21) Somorjai, G. A.; Materer, N. Surface structures in ammonia synthesis. Top. Catal. 1994, 1, 215-231.

(22) Strongin, D. R.; Carrazza, J.; Bare, S. R.; Somorjai, G. A. The importance of C7 sites and surface roughness in the ammonia-synthesis reaction over iron. J. Catal. 1987, $103,213-215$.

(23) Sabatier, P. Hydrogenations et deshydrogenations par catalyse. Ber. Dtsch. Chem. Ges. 1911, 44, 1984-2001.

(24) Nørskov, J. K.; Bligaard, T.; Rossmeisl, J.; Christensen, C. H. Towards the computational design of solid catalysts. Nat. Chem. 2009, 1, 37-46.

(25) Wolcott, C. A.; Medford, A. J.; Studt, F.; Campbell, C. T. Degree of rate control approach to computational catalyst screening. J. Catal. 2015, 330, 197-207.

(26) An, Q.; Shen, Y. D.; Fortunelli, A.; Goddard III, W. A. QM-mechanism-based hierarchical high-throughput in silico screening catalyst design for ammonia synthesis.

J. Am. Chem. Soc. 2018, 140, 17702-17710.

(27) Qian, J.; Fortunelli, A.; Goddard III, W. A. Effect of Co doping on mechanism and kinetics of ammonia synthesis on Fe(111) surface. J. Catal. 2019, 370, 364-371.

(28) Mcdonald, M.; Fuller, J.; Fortunelli, A.; Goddard III, W. A.; An, Q. Highly efficient $\mathrm{Ni}$-doped iron catalyst for ammonia synthesis from quantum-mechanics-based hierarchical high-throughput catalyst screening. J. Phys. Chem. C 2019, 123, 1737517383.

(29) Hagen, S.; Barfod, R.; Fehrmann, R.; Jacobsen, C. J. H.; Teunissen, H. T.; Ståhlb, K.; Chorkendorff, I. New efficient catalyst for ammonia synthesis: barium-promoted cobalt on carbon. Chem. Commun. 2002, 1206-1207

(30) Kresse, G.; Hafner, J. Ab initio molecular dynamics for liquid metals. Phys. Rev. $B$ 1993, 47, 558-561.

(31) Kresse, G.; Furthmüller, J. Efficiency of ab-initio total energy calculations for metals and semiconductors using a plane-wave basis set. Comput. Mater. Sci. 1996, 6, 15-50.

(32) Kresse, G.; Furthmüller, J. Efficient iterative schemes for ab initio total-energy calculations using a plane-wave basis set. Phys. Rev. B 1996, 54, 11169-11186.

(33) Kresse, G.; Joubert, D. From ultrasoft pseudopotentials to the projector augmented-wave method. Phys. Rev. B 1999, 59, 1758-1775.

(34) Perdew, J. P.; Burke, K.; Ernzerhof, M. Generalized gradient approximation made simple. Phys. Rev. Lett. 1996, 77, 3865-3868.

(35) Perdew, J. P.; Burke, K.; Ernzerhof, M. Erratum: generalized gradient approximation made simple. Phys. Rev. Lett. 1997, 78, 1396-1396.

(36) Grimme, S.; Antony, J.; Ehrlich, S.; Krieg, H. A consistent and accurate ab initio parametrization of density functional dispersion correction (DFT-D) for the 94 elements H-Pu. J. Chem. Phys. 2010, 132, 154104.

(37) Johnson, E. R.; Becke, A. D. A post-hartree-fock model of intermolecular interactions: inclusion of higher-order corrections. J. Chem. Phys. 2006, 124, 174104.

(38) Kittel, C. Introduction to Solid State Physics; Wiley: New York, 1996. 
(39) Baroni, S.; Giannozzi, P.; Testa, A. Green's-function approach to linear response in solids. Phys. Rev. Lett. 1987, 58, 1861-1864.

(40) Dove, M, T. Introduction to Lattice Dynamics; Cambridge University Press: Cambridge (UK), 1993.

(41) Ertl G.; Lee S. B.; Weiss M. Adsorption of nitrogen on potassium promoted iron (111) and (100) surfaces. Surf. Sci. 1982, 114, 527-545.

(42) Von Goldbeck, O. K. "Fe-Si: Iron-silicon," in Iron Binary Phase Diagrams; Springer: Berlin; 1982, 136-139.

(43) Kua, J.; Faglioni, F.; Goddard III, W. A. Thermochemistry for hydrocarbon intermediates chemisorbed on metal surfaces: $\mathrm{CH}_{\mathrm{n}-\mathrm{m}}\left(\mathrm{CH}_{3}\right)_{\mathrm{m}}$ with $\mathrm{n}=1,2,3$ and $\mathrm{m} \leqslant \mathrm{n}$ on Pt, Ir, Os, Pd, Rh, and Ru. J. Am. Chem. Soc. 2000, 122, 2309-2321. 
TOC Figure

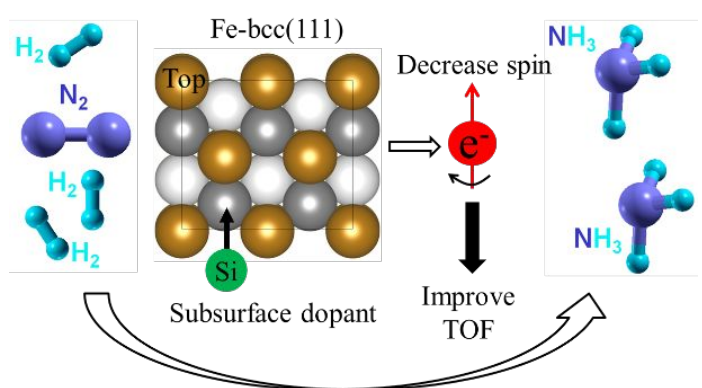

